\title{
A comparison of new measurements of total monoterpene flux with improved measurements of speciated monoterpene flux
}

\author{
A. Lee $^{1}$, G. W. Schade ${ }^{2}$, R. Holzinger ${ }^{1}$, and A. H. Goldstein ${ }^{1}$ \\ ${ }^{1}$ Department of Environmental Science, Policy, and Management, University of California, Berkeley, 151 Hilgard Hall \# \\ 3110, Berkeley, CA 94720-3110, USA \\ ${ }^{2}$ Institute of Environmental Physics, University of Bremen, NW1, Otto-Hahn-Allee 1, D-28359 Bremen, Germany
}

Received: 29 October 2004 - Published in Atmos. Chem. Phys. Discuss.: 1 December 2004

Revised: 8 February 2005 - Accepted: 11 February 2005 - Published: 15 February 2005

\begin{abstract}
Many monoterpenes have been identified in forest emissions using gas chromatography (GC). Until now, it has been impossible to determine whether all monoterpenes are appropriately measured using GC techniques. We used a proton transfer reaction mass spectrometer (PTR-MS) coupled with the eddy covariance (EC) technique to measure mixing ratios and fluxes of total monoterpenes above a ponderosa pine plantation. We compared PTR-MS-EC results with simultaneous measurements of eight speciated monoterpenes, $\beta$-pinene, $\alpha$-pinene, 3 -carene, d-limonene, $\beta$-phellandrene, $\alpha$-terpinene, camphene, and terpinolene, made with an automated, in situ gas chromatograph with flame ionization detectors (GC-FID), coupled to a relaxed eddy accumulation system (REA). Monoterpene mixing ratios and fluxes measured by PTR-MS averaged $30 \pm 2.3 \%$ and $31 \pm 9.2 \%$ larger than by GC-FID, with larger mixing ratio discrepancies between the two techniques at night than during the day. Two unidentified peaks that correlated with $\beta$-pinene were resolved in the chromatograms and completely accounted for the daytime difference and reduced the nighttime mixing ratio difference to $20 \pm 2.9 \%$. Measurements of total monoterpenes by PTR-MS-EC indicated that GC-FID-REA measured the common, longer-lived monoterpenes well, but that additional terpenes were emitted from the ecosystem that represented an important contribution to the total mixing ratio above the forest at night.
\end{abstract}

\section{Introduction}

Monoterpenes are a large class of biogenic $\mathrm{C}_{10} \mathrm{H}_{16}$ hydrocarbons which include the commonly observed species $\alpha$-pinene and $\beta$-pinene. Monoterpenes are emitted from conifers as well as broad-leaved trees (Kesselmeier and

Correspondence to: A. Lee

(alee@ nature.berkeley.edu)
Staudt, 1999). They are highly reactive and can be oxidized by ozone $\left(\mathrm{O}_{3}\right)$ and the hydroxyl and nitrate radicals, with lifetimes that range from days to minutes (Fuentes et al., 2000). In addition to their influence on the oxidative capacity of the atmosphere, monoterpene oxidation products can partition to the particle phase and contribute to secondary organic aerosol (SOA) (e.g. Kavouras et al., 1999; Makela et al., 1997; Griffin et al., 1999). These SOA represent a natural source of aerosol to the atmosphere that impact regional air quality and global climate (Andreae and Crutzen, 1997), therefore, quantitative and qualitative knowledge of terpene emission is essential to reduce the uncertainty in biogenic production of SOA.

Ecosystem scale monoterpene fluxes to the atmosphere have been measured as a sum of the individual fluxes of a few speciated monoterpenes, using GC-FID coupled with the flux similarity approach (e.g. Schade et al., 1999; Rinne et al., 2000) or coupled with the relaxed eddy accumulation technique (e.g. Greenberg et al., 2003; Schade and Goldstein, 2003). Recently, the development of the fast-response PTRMS by Werner Lindinger and his group at the University of Innsbruck in Austria, has allowed the use of eddy covariance techniques for measuring total monoterpene fluxes (Karl et al., 2004; Spirig et al., 2004). The ability to measure total monoterpene fluxes is significant because models of tropospheric $\mathrm{O}_{3}$ and SOA production rely on flux measurements of a few species of monoterpenes, however, it is currently unknown if speciated flux measurements of a limited number of monoterpenes represent the impact of total monoterpenes to the atmosphere. In addition to monoterpenes, other terpene compounds, such as sesquiterpenes and oxygenated terpenes, also affect tropospheric chemistry (Fuentes et al., 2000).

In this paper, we address the question of whether abovecanopy fluxes of monoterpenes are well represented by GCFID-REA measurements of a limited number of monoterpene species. We improved our speciated monoterpene mixing ratio and flux measurements by increasing the number

(c) 2005 Author(s). This work is licensed under a Creative Commons License. 
of monoterpene species routinely quantified by our GC-FIDREA from four to eight, and simultaneously made ecosystem scale measurements of total monoterpene fluxes using a PTR-MS-EC. Comparison of these measurements help determine if other monoterpene compounds, in addition to the eight species quantified by the GC-FID, are emitted from the forest and detected by the PTR-MS in the measurements of total monoterpenes.

\section{Experimental}

We report on a four day period in August 2002 of total and speciated monoterpene mixing ratios and fluxes made simultaneously above a young ponderosa pine (Pinus ponderosa L.) plantation (planted in 1990), interspersed with a few individuals of white fir, Douglas fir, incense cedar, and California black oak. The site is located at $1315 \mathrm{~m}$ elevation on the western slope of the Sierra Nevada, California $\left(35^{\circ} 53^{\prime} 42.9^{\prime \prime} \mathrm{N}, 120^{\circ} 37^{\prime} 57.9^{\prime \prime} \mathrm{W}\right)$. Roughly $90 \%$ of the tower footprint was in the plantation, within $200 \mathrm{~m}$ from the tower (Goldstein et al., 2000). Mixing ratios and fluxes of $\mathrm{CO}_{2}, \mathrm{H}_{2} \mathrm{O}, \mathrm{O}_{3}$, and VOCs were made since 1998, and are reported in detail elsewhere (e.g. Lamanna and Goldstein, 1999; Goldstein et al., 2000; Bauer et al., 2000; Schade and Goldstein, 2001). Previous measurements reported monoterpene mixing ratios and fluxes for four species of monoterpenes, $\beta$-pinene, $\alpha$-pinene, 3 -carene, and d-limonene, using the dual channel GC-FID coupled to the flux similarity approach (Schade et al., 1999), or relaxed eddy accumulation (Schade and Goldstein, 2003). Speciated monoterpene fluxes from this site show a temperature and humidity dependence (Schade et al., 1999).

Temperature and 3-D wind speeds were measured using a sonic anemometer (Campbell Scientific, Logan, UT), mounted $12 \mathrm{~m}$ above ground level, $5 \mathrm{~m}$ above the forest canopy. The sample inlet was located at the top of the tower, adjacent to the sonic anemometer. Air was pulled at $10 \mathrm{~L} \mathrm{~min} \mathrm{~m}^{-1}$ through a $2 \mu \mathrm{m}$ Teflon particulate filter, and brought down, using $\frac{1}{4}$ inch ID Teflon tubing, to a temperature controlled container. Air was sub-sampled by the GCFID and PTR-MS from the same sample line, and the same sonic anemometer was used to control the REA valve system and for EC flux calculations. The GC-FID-REA system was calibrated with an internal standard, by diluting ppm-level n-octane in UHP $\mathrm{N}_{2}$ (Scott-Marrin, Inc., Riverside, CA) directly into the sample line at the top of the tower, downstream of the particulate filter. Monoterpenes were automatically and simultaneously calibrated on both instruments every ten hours, rotating between three separate ppmlevel monoterpene standards, diluted into the sample line inside the temperature-controlled container to achieve lowppb concentrations, before sub-sampling to the GC-FID and PTR-MS. One standard cylinder contained monoterpenes as a mixture of $\alpha$-pinene, 3-carene, and d-limonene in UHP $\mathrm{N}_{2}$, and two cylinders contained monoterpenes singly as either $\alpha$-pinene or $\beta$-pinene in UHP $\mathrm{N}_{2}$. Blank measurements were run on the GC-FID every ten hours, and were run for five minutes each hour on the PTR-MS, by sampling zero air (AADCO, Clearwater, FL).

For measurements of total monoterpene flux, the PTRMS acquired 3-D wind speed, temperature, and monoterpene concentration (in counts per second) at $2 \mathrm{~Hz}$, and fluxes were calculated according to EC from the mean covariance between deviations of the vertical wind speed and the monoterpene mixing ratio calculated from the 30 -min time series of the de-meaned, de-trended, tapered, and appropriately lagged data (Stull, 1988). The PTR-MS (Ionicon Analytik, Innsbruck, Austria) is described in detail elsewhere (Lindinger et al., 1998). Briefly, the PTR-MS is a chemical ionization technique that uses $\mathrm{H}_{3} \mathrm{O}^{+}$to transfer a proton from water to the compound of interest, thus, any compound with a proton affinity higher than water will be ionized and detected by the quadrupole mass spectrometer. For monoterpenes, fragmentation occurs but usually produces only one fragment ion, so for most monoterpenes $>99 \%$ of the signal is detected as $\mathrm{C}_{10} \mathrm{H}_{16} \mathrm{H}^{+}$and $\mathrm{C}_{6} \mathrm{H}_{8} \mathrm{H}^{+}$ions, which are monitored at $\mathrm{m} / \mathrm{z} 137$ and 81, respectively (Tani et al., 2003). We monitored $\mathrm{m} / \mathrm{z} 81$ and 137, each with a dwell time of $0.2 \mathrm{~s}$, primary ions $\mathrm{H}_{3} \mathrm{O}^{+}$and $\mathrm{H}_{2} \mathrm{OH}_{3} \mathrm{O}^{+}$, and recorded information from five analog channels on 3-D wind speed, temperature, and drift tube pressure of the PTR-MS, so that one measurement cycle was completed in $0.5 \mathrm{~s}$, with a disjunct sampling frequency for each $\mathrm{m} / \mathrm{z}$ of $5 \mathrm{~Hz}$. A lag time between the wind and concentration measurements of $\sim 4 \mathrm{~s}$ was measured by popping balloons filled with acetone-enriched air at the co-located sonic anemometer and sample inlet, and subtracting the time difference between the sonic and acetone spikes. This method agreed well with the lag time inferred through analysis of the PTR-MS data by finding the time difference that produced the best correlation between deviations in wind speed ( $w^{\prime}$ ) and deviations in $\mathrm{m} / \mathrm{z} 81$ or 137 count rates ( $\left.c^{\prime}\right)$.

Calculated mixing ratios were corrected against the single $\beta$-pinene and mix of the $\alpha$-pinene, 3 -carene, and d-limonene standards to account for uncertainties in the reaction rate constants, and the mass dependant transmission efficiency of the mass spectrometer. Additionally, this correction ensured that PTR-MS and GC-FID measurements were calibrated against the same standard. While the mass based detection of the PTR-MS is an important distinction from the GC-FID because it detects all compounds with an $\mathrm{m} / \mathrm{z}$ of 137 and 81 , and thus, is a measure of total monoterpenes in the air sample, an important consideration is the possibility of non-monoterpene compounds occurring at the monoterpene masses. We observed that sesquiterpenes $(m / z=205)$ also produce fragments at $\mathrm{m} / \mathrm{z} 137$ and 81 , with ratios of the fragment to $\mathrm{m} / \mathrm{z} 205$ count rate varying significantly between $\beta$ caryophyllene and $\alpha$-humulene, from 0.11 (cps 137/cps 205) and 0.26 (cps 81/cps 205) for $\alpha$-humulene, and 0.30 and 0.62 for $\beta$-caryophyllene. The sesquiterpenes, $\alpha$-longipinene, 
longifolene, and germacrene D have been identified in the oleoresin distillates of ponderosa pine (Himejima et al., 1992), however the sesquiterpene signal at $\mathrm{m} / \mathrm{z} 205$, monitored in Summer 2003, never exceeded 5\% of the signal at $\mathrm{m} / \mathrm{z} 81$ and 137. Therefore, fragmentation of sesquiterpenes onto the monoterpene masses should only be a minor issue. We must also consider the contribution of other non-terpene species to the count rates of $\mathrm{m} / \mathrm{z} 137$ or 81 . However, because the slope of the correlations between masses 137 and 81 from ambient air compared with the slope of the correlations between masses 137 and 81 from the standard additions where within $7 \%$, we conclude that any such interference was small compared to the monoterpene signal.

Speciated flux measurements of eight monoterpene species were made using a dual channel GC-FID combined with the relaxed eddy accumulation (REA) technique. The GC-FID-REA are described in detail elsewhere (Lamanna and Goldstein, 1999; Schade and Goldstein, 2001). Air was sub-sampled from the inlet line at $20 \mathrm{~mL} \mathrm{~min}^{-1}$ for $30 \mathrm{~min}$. Fast response REA segregator valves (Bio-Chem Valve Inc., Boonton, NJ) were controlled by the sonic anemometer and CR23x datalogger (Campbell Scientific, Logan, UT), and partitioned sample air into updraft or downdraft channels according to the sign of the vertical wind speed obtained at $10 \mathrm{~Hz}$. Because of the potential smearing of small eddies inside our sampling line, a deadband $\left(0.4 \sigma_{w}\right)$ was applied to reduce the sampling of these small eddies (Lenschow and Raupach, 1991). Sample air was scrubbed of ambient $\mathrm{O}_{3}$ as it passed through KI-coated glass wool, and was cold trapped in $1 / 16$ inch Silcosteel tubes (Restek Inc., Bellafonte, PA) packed sequentially with glass beads, Tenax TA, and Carbopack X (Supelco, St. Louis, MO). The two sample tubes were heated from $-10^{\circ} \mathrm{C}$ to $220^{\circ} \mathrm{C}$ within $20 \mathrm{~s}$ to desorb the trapped compounds into He carrier gas, which delivered the samples to two RTX-5 chromatography columns. The monoterpenes were identified according to their retention times on the columns, and quantified by the two flame ionization detectors. The n-octane served as an internal standard to correct for potential leaks or changes in instrument response. Using the monoterpene standards, an instrument response factor was calculated according to the method described by Lamanna and Goldstein (1999), and applied uniformly to all monoterpenes. The measured response factors calculated from the individual standard additions of $\alpha$ - and $\beta$-pinene were within $10 \%$ of this instrument response factor based on n-octane. Monoterpene species for which cylinder standards were unavailable were identified by waving the pure compound at the inlet. These compounds included camphene, $\beta$-phellandrene, and $\gamma$-terpinene (from L. Cool, Forest Products Laboratory, University of California, Berkeley), myrcene, $\alpha$-terpinene, and terpinolene (Sigma-Aldrich, St. Louis, MO). Although we could identify ten monoterpene species, only eight were included in this analysis, as myrcene and $\gamma$-terpinene peaks were typically below our detection limit. Fluxes of the monoterpene species were calcu- lated from:

$F=b \sigma_{w}\left(C_{u}-C_{d}\right)$

where $\mathrm{C}_{u}$ and $\mathrm{C}_{d}$ are the mixing ratios of the updraft and downdraft channels, respectively, $\sigma_{w}$ is the standard deviation of the vertical wind speed, and $b$ is determined from measurements of the sensible heat flux and air temperature (Bowling et al., 1998). Values for $\mathrm{b}$ were set to the mean value $(0.45 \pm 0.02$, mean \pm standard deviation) for times when the sensible heat fluxes were within $\pm 30 \mathrm{~W} \mathrm{~m}^{-2}$, or when $\mathrm{b}$ was outside $\mathrm{a} \pm 0.2$ interval of the mean (Schade and Goldstein, 2001). Because the GC-FID-REA resolved $\beta$ pinene fluxes best, the flux of the sum of speciated monoterpenes was calculated by scaling the $\beta$-pinene flux by the slope of a scatter plot of the mixing ratio of each speciated monoterpene versus $\beta$-pinene. This process did not significantly change the mean fluxes of the speciated monoterpenes, but increased the precision of the speciated monoterpene fluxes for each 30 min measurement period.

We estimated the uncertainty of the mixing ratios from the PTR-MS based on the counting statistics of the instrument and the uncertainty in the delivery of the monoterpene calibration standards. The percent uncertainty in the measured count rate due to counting statistics is defined as the square root of the total signal divided by the total signal, where the total signal is the count rate, in counts per second, times the dwell time. Because mixing ratios were calculated as the mean over a $30 \mathrm{~min}$ period, uncertainties resulting from counting statistics were calculated for each $30 \mathrm{~min}$ period. The uncertainty of the calibration factor was determined using Gaussian Error Propagation to combine the uncertainty from counting statistics with the other sources of uncertainty in the calculation of the calibration factor, including the uncertainty in $\beta$-pinene standard concentration $( \pm 2 \%)$, the concentrations of the mixture of three monoterpenes $( \pm 5 \%)$, and the $\pm 1 \%$ uncertainty, at full scale, of the two mass flow controllers (MKS Instruments Inc., Andover, MA). For each 30min average count rate from the PTR-MS, uncertainties from counting statistics ranged from 1 to $4.8 \%$ with a mean uncertainty of $2.3 \%$. Combining the uncertainty from counting statistics with the calibration uncertainty, the mean uncertainty in the total monoterpene mixing ratio measurements was $4.9 \%$ with a range of 2.4 to $11.3 \%$. Additionally, it is important to note that the uncertainty estimate is based on four monoterpenes, and the actual uncertainty is somewhat larger because the total monoterpene measurement consists of a mix of monoterpenes whose reaction rate constants and sensitivity in the PTR-MS contain additional uncertainty.

The mean \pm standard deviation of the background counts during measurement of zero air for $\mathrm{m} / \mathrm{z} 81$ (1.5 \pm 2.7 counts per second, cps) and $137(1.0 \pm 2.2 \mathrm{cps})$ were not significantly different from zero. Given our primary ion signal of 2-4 million cps, the sensitivity of the PTR-MS to monoterpenes, and the $1 \sigma$ (standard deviation) of the background counts, the detection limit for total monoterpenes, measured as the 


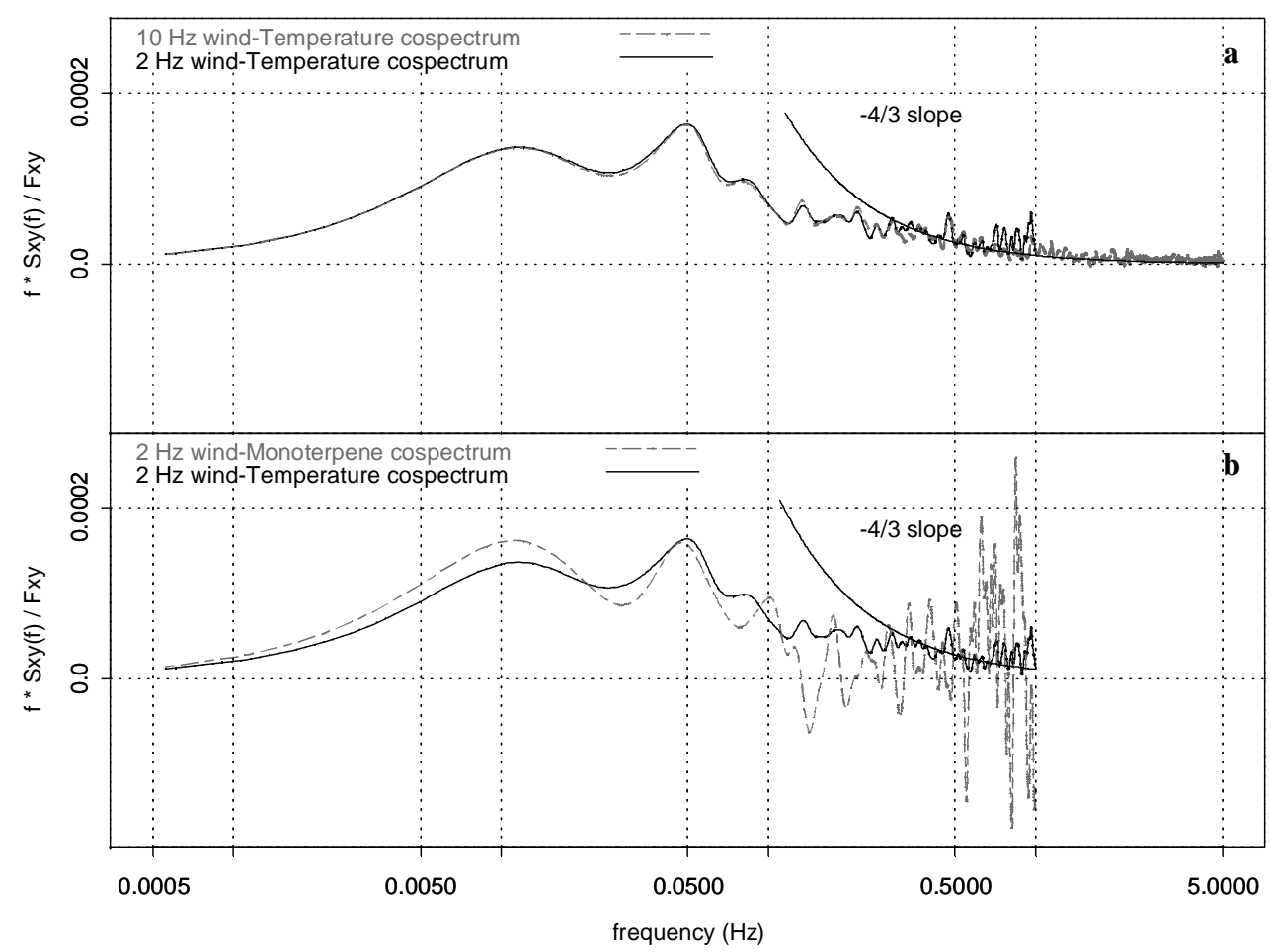

Fig. 1. Normalized cospectra (a) of $10 \mathrm{~Hz}$ and $2 \mathrm{~Hz}$ wind-temperature and (b) $2 \mathrm{~Hz}$ wind-temperature and wind-monoterpene from day 214 (11:00 PST) plotted on a semi-log scale.

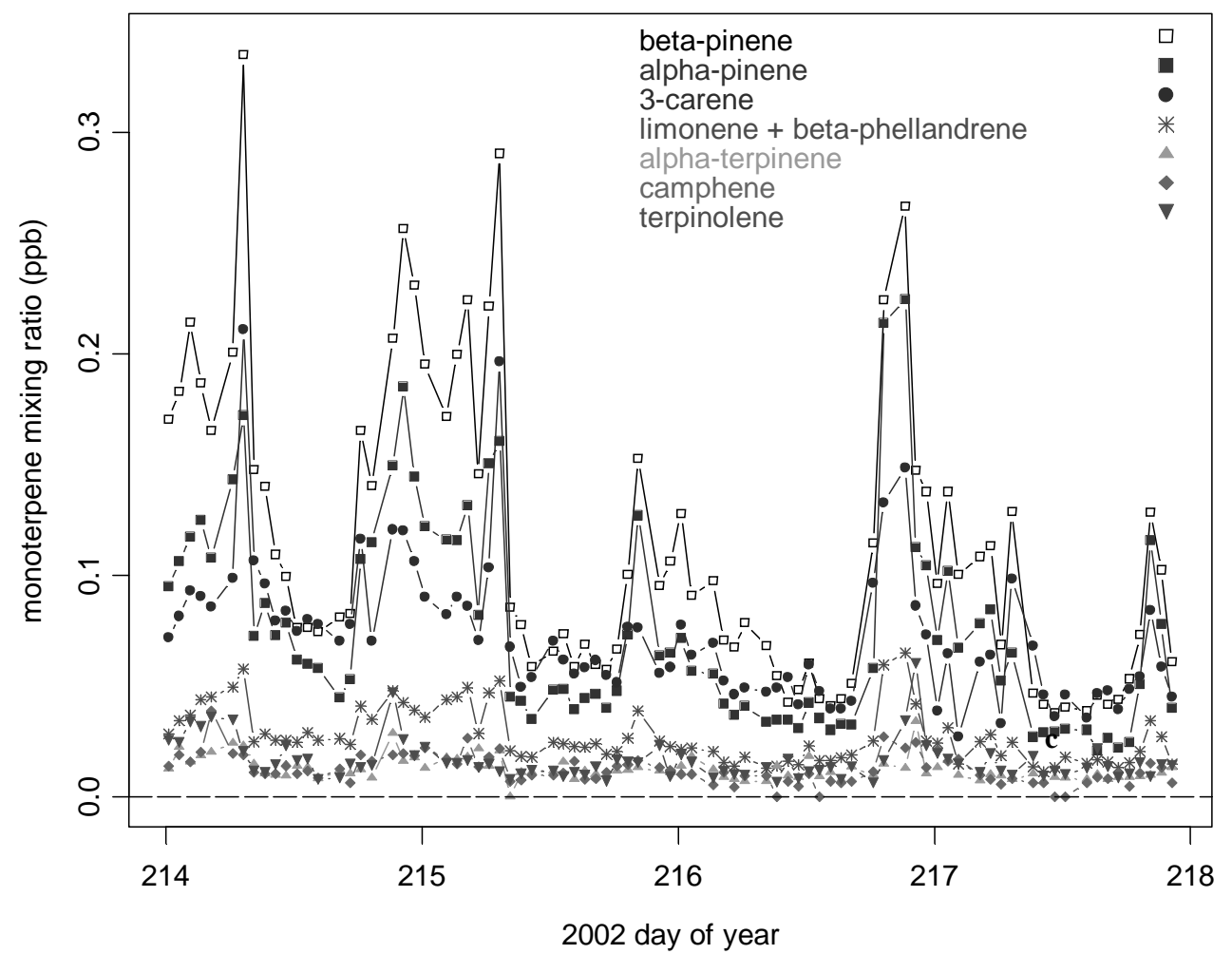

Fig. 2. Diurnal cycle of speciated monoterpene mixing ratios. 
sum of $\mathrm{m} / \mathrm{z} 81$ and 137, during this measurement period was $\sim 144$ ppt. The high detection limit is based on the large standard deviation of the background counts, resulting from the poor counting statistics generated from the short $0.2 \mathrm{~s}$ dwell time. Except for one half-hour period, total monoterpene mixing ratios measured by PTR-MS always exceed the detection limit.

Gaussian Error Propagation was also used to estimate the uncertainty of the mixing ratios and fluxes measured by the GC-FID-REA system. Uncertainty in the monoterpene concentration in the standard cylinders was combined with uncertainty in the accuracy of the flow controllers. In addition, the deviation of the measured response factors of the monoterpene standards from the instrument response factor (Lamanna and Goldstein, 1999) was included in the uncertainty estimate for each monoterpene species. The mean uncertainty in the speciated monoterpene mixing ratios ranged from $17 \%$ for $\alpha$ - and $\beta$-pinene, to $34 \%$ for 3 -carene. Given the response factor for monoterpenes in the GC-FID, the detection limit for speciated monoterpenes was $8 \mathrm{ppt}$. Mixing ratios of the dominant monoterpenes were always above the detection limit.

Because we calibrated both the GC-FID and the PTR-MS instruments with the same ppm-level standards diluted to ppb levels in the same sample stream, any error in the absolute concentration of the standards and measured flow rates for the dilution system would be propagated identically through both measurements. Thus, our conclusions regarding percent differences in concentrations measured by the two methods should be more accurate than the above uncertainty analysis implies. A critical difference in instrument calibration would occur only if the GC-FID or PTR-MS system responded significantly differently to monoterpenes that we could not calibrate directly versus compounds for which we had quantitative standards.

Potential underestimates in EC flux measurements due to loss of high frequency signals are typically assessed using spectral analysis of the time series data. To examine the potential bias in the calculated flux associated with our $2 \mathrm{~Hz}$ sampling frequency, we sub-sampled vertical wind and temperature logged at $10 \mathrm{~Hz}$ by the CR23x datalogger, to match our $2 \mathrm{~Hz}$ sampling protocol for the PTR-MS. The cospectra are plotted on a semi-log scale so that the area under the curve is proportional to the covariance (Stull, 1988). Figure 1a shows that the $2 \mathrm{~Hz}$ cospectrum is slightly elevated and noisier compared to the $10 \mathrm{~Hz}$ cospectrum at higher frequencies, suggesting that aliasing may cause the folding of high frequency energy onto lower frequencies, resulting in a distortion of the $2 \mathrm{~Hz}$ cospectrum. Because of the lower sampling frequency and the noise associated with lower frequency sampling, we expected to underestimate the calculated flux from the $2 \mathrm{~Hz}$ data compared to the $10 \mathrm{~Hz}$ data, however, the sensible heat fluxes calculated at $2 \mathrm{~Hz}$ were not consistently lower than at $10 \mathrm{~Hz}$, and agreed within $\pm 10 \%$, despite the noise.
The correction for high frequency flux loss due to the inertia of sensors can be estimated by applying an empiricallydetermined time constant, which acts as a low pass filter, to the "ideal" wind-temperature cospectrum $\left(\overline{w^{\prime} T^{\prime}}\right)$ so that the transformed $\overline{w^{\prime} T^{\prime}}$ mimics the non-ideal cospectrum of $\overline{w^{\prime} \text { monoterpene }}\left(\overline{w^{\prime} M^{\prime}}\right.$; Fig. 1b) (e.g. Bauer et al., 2000). The ratio of the measured $\overline{w^{\prime} T^{\prime}}$ and the transformed $\overline{w^{\prime} T^{\prime}}$ represents the correction factor for the monoterpene flux. The normalized cospectra for the $2 \mathrm{~Hz} \overline{w^{\prime} T^{\prime}}$ and $\overline{w^{\prime} M^{\prime}}$ (Fig. 1b) show that both cospectra follow the expected $-{ }^{4} / 3$ slope in the inertial sub-range, but the $\overline{w^{\prime} M^{\prime}}$ cospectra suffers from noise at higher frequencies. Median correction factors calculated for the $2 \mathrm{~Hz} \overline{w^{\prime} M^{\prime}}$ data were small $(<10 \%)$, but highly variable due to the high frequency noise in the cospectra. We chose not to apply these relatively small corrections based on the cospectral densities, which would have slightly increased the difference between the fluxes measured by PTR-MS-EC and GC-FID-REA.

\section{Results and discussion}

The diurnal cycle of the eight speciated monoterpenes shows that $\beta$-pinene, $\alpha$-pinene, and 3 -carene are the dominant 3 monoterpenes emitted from the site, with smaller contributions from limonene $+\beta$-phellandrene, terpinolene, $\alpha$ terpinene, and camphene (Fig. 2). Measurements of total (PTR-MS) and the sum of speciated (GC-FID) monoterpenes over the four-day period in early August generally agree well (Fig. 3a), but show higher mixing ratios measured by the PTR-MS. Mixing ratios of total monoterpenes averaged $30 \pm 2.3 \%$ (mean \pm standard error) larger than mixing ratios of the sum of eight monoterpene species (Fig. 4a), which is an important contribution to monoterpene mixing ratio, considering $\beta$-pinene, the dominant monoterpene, contributes $40 \pm 1 \%$ to the sum of the eight monoterpenes detected by GC-FID. Total monoterpene mixing ratios were $33 \pm 3 \%$ larger at night and $15 \pm 3 \%$ larger during the day (08:00-16:00 PST) than the sum of speciated monoterpenes (Fig. 4a). The time series of the percent difference between the mixing ratios measured by PTR-MS and GC-FID, plotted with $\mathrm{O}_{3}$ mixing ratio, show that periods when the PTRMS measures significantly more monoterpene than the GCFID coincide with periods of low $\mathrm{O}_{3}$ mixing ratio (Fig. 3b). The diurnal cycle of monoterpene fluxes followed the diurnal temperature cycle, with higher fluxes when temperatures were higher (Fig. 3c). Total monoterpene fluxes measured by the PTR-MS-EC were $31 \pm 9 \%$ higher than those measured by GC-FID-REA (Fig. 4b), with greater uncertainty in the slope of the correlation than the mixing ratios. Due to the uncertainty associated with nighttime flux measurements, there was no significant difference $(p=0.45)$ between the daytime and nighttime difference in slope from the regression of flux measurements made by PTR-MS-EC and GC-FID-REA (Fig. 4b). 

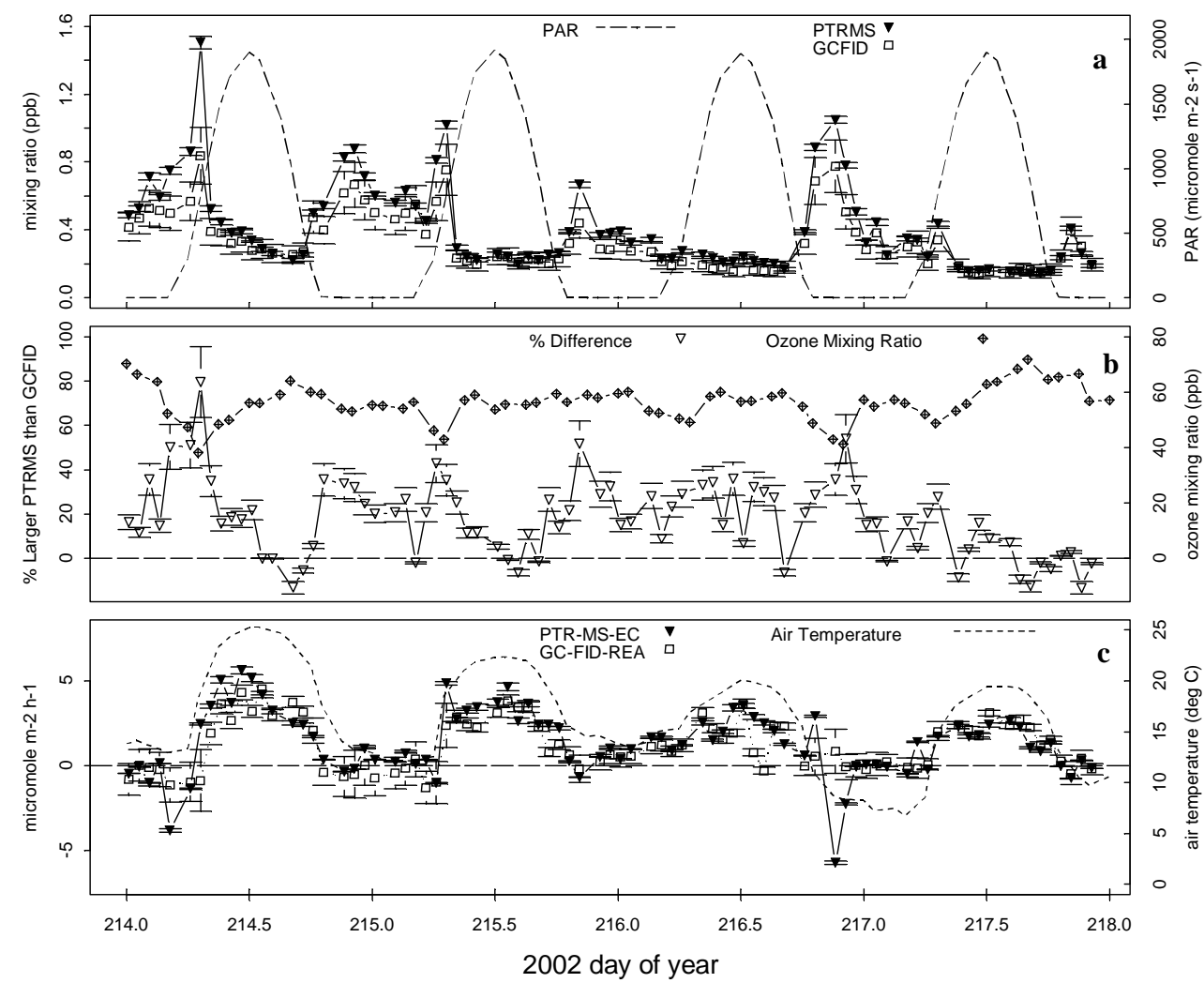

Fig. 3. (a) Total monoterpene mixing ratios and (c) fluxes measured by PTR-MS are greater than the sum of eight monoterpene species measured by GC-FID. (b) Diurnal cycle of the percent difference between PTR-MS and GC-FID mixing ratios, plotted with $\mathrm{O}_{3}$ mixing ratio, show that the PTR-MS measures more monoterpenes than the GC-FID, particularly when $\mathrm{O}_{3}$ mixing ratios are lower.

Careful inspection of the chromatograms showed that 610 small peaks were resolved by the GC-FID in addition to the eight identified monoterpenes, and two of those peaks were correlated with $\beta$-pinene mixing ratios, with slopes of the correlation that were significantly different from zero. Taking the area of those two unidentified peaks, and applying the GC-FID response factor used for the identified monoterpenes, the resulting mixing ratios reduced the slope of the correlation between total and sum of speciated monoterpenes to $0.997 \pm 0.03$ during the day, and $1.20 \pm 0.03$ at night. Thus, PTR-MS measurements of total monoterpenes and GC-FID measurements of eight identified monoterpenes and 2 unidentified potential monoterpenes agree well during the day, but at night, additional compounds were detected by PTR-MS that were not resolved by GC-FID. The detection of these additional compounds by PTR-MS at night but not during the day suggests that these compounds are emitted in a temperature dependent manner, and undergo complete daytime photochemical loss before they reach the height of our sample inlet $5 \mathrm{~m}$ above the forest canopy. Daytime oxidation of the unidentified terpenes is consistent with observations at this field site in 2003 of oxidation products with highest concentrations above the canopy, indicating a strong local, daytime source (Holzinger et al., 2005). Although we expect that the signals on $\mathrm{m} / \mathrm{z} 81$ and 137 are not significantly influenced by interferences from other compounds, we cannot rule out the possibility that other terpene compounds might interfere with the monoterpene signal, and fragment in a similar way as the monoterpenes so that the ratio of $\mathrm{m} / \mathrm{z} 81$ to 137 remains relatively stable.

Figure 5 shows the exponential relationship between air temperature and monoterpene flux for the four-day period from 08:00 to 16:00 PST. Guenther et al. (1993) describe the temperature dependence of flux according to:

$F=F_{30} \exp [\beta(T-30)]$

where $\mathrm{F}_{30}$ represents the basal emission rate at $30^{\circ} \mathrm{C}$, T represents the air temperature in ${ }^{\circ} \mathrm{C}$, and $\beta$ is the temperature dependence coefficient, with units of ${ }^{\circ} \mathrm{C}^{-1}$, where higher $\beta$ values represent a larger change in flux per ${ }^{\circ} \mathrm{C}$ increase. The values for $\mathrm{F}_{30}$ and $\beta$ that produce the best log-normal linear least squares fit to the measured fluxes are: $\mathrm{F}_{30}=8.5 \pm 1.1 \mu$ mole terpene $\mathrm{m}^{-2} \mathrm{~h}^{-1}$ and $\beta=0.13 \pm 0.02^{\circ} \mathrm{C}^{-1}$ for the total monoterpene flux, and $\mathrm{F}_{30}=5.1 \pm 1.2 \mu$ mole terpene $\mathrm{m}^{-2} \mathrm{~h}^{-1}$ and $\beta=0.08 \pm 0.02^{\circ} \mathrm{C}^{-1}$ for the flux of the sum of speciated monoterpenes. Values for $\mathrm{F}_{30}$ reported by (Schade and Goldstein, 2003), from the same experimental site using GC-FIDREA, for the sum of $\alpha$-pinene, $\beta$-pinene, and 3 -carene were 

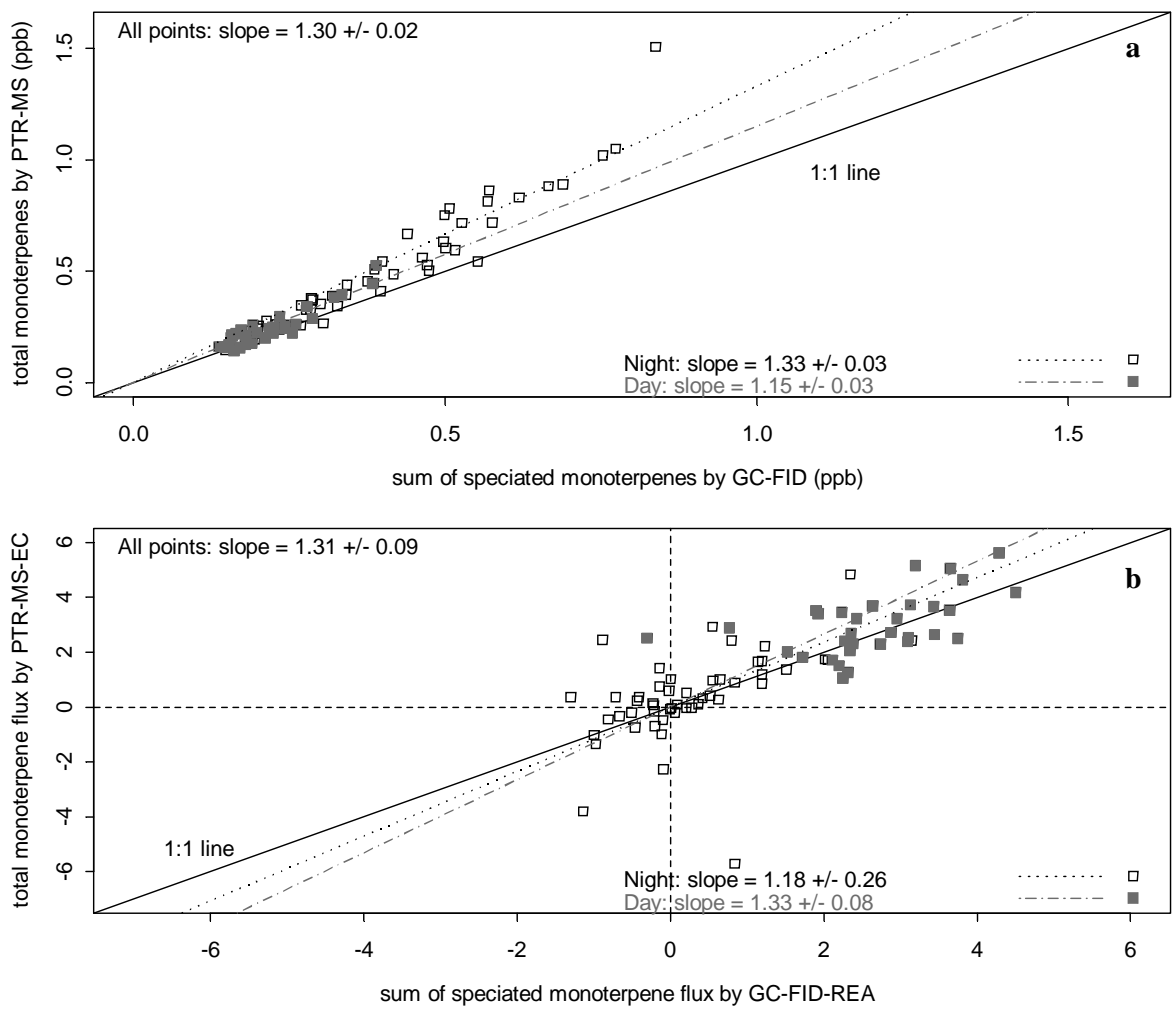

Fig. 4. Correlation between mixing ratios and fluxes measured by GC-FID-REA and PTR-MS-EC. (a) The difference in mixing ratios between the PTR-MS and GC-FID were smaller during the daytime (08:00-16:00 PST) than at night, (b) but there was no significant difference between daytime and nighttime slopes of the correlation between the PTR-MS-EC and GC-FID-REA measurements ( $p=0.45$ ).

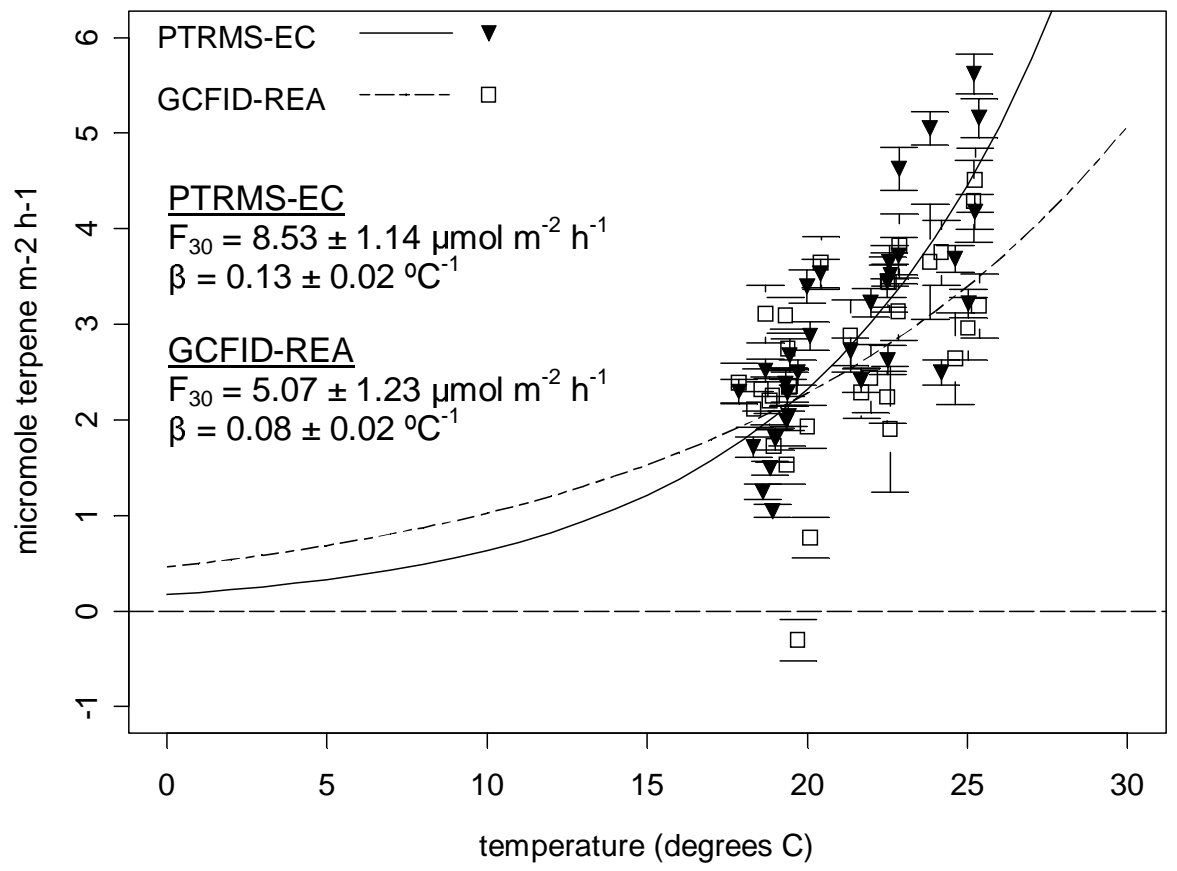

Fig. 5. Temperature dependence of total and speciated monoterpene fluxes measured during daytime periods (08:00-16:00 PST). 
$5.9 \mu$ mole terpene $\mathrm{m}^{-2} \mathrm{~h}^{-1}$ before thinning of the forest in Spring 2000, and $6.7 \mu$ mole terpene $\mathrm{m}^{-2} \mathrm{~h}^{-1}$ for Summer 1999, and are in good agreement with those measured by GC-FID-REA and PTR-MS-EC for this four-day period. The values for $\beta$ are within the range of previously reported values of $0.06-0.2^{\circ} \mathrm{C}^{-1}$ (Guenther et al., 1993; Rinne et al., 2002 and references therein). For $\alpha$-pinene, $\beta$-pinene, and 3carene fluxes, Schade and Goldstein (2003) reported $\beta$ coefficients for individual monoterpenes that ranged from 0.095 to $0.14^{\circ} \mathrm{C}^{-1}$, with lowest $\beta$ values for $\alpha$-pinene and highest for 3-carene. Values for $\beta$ exhibit spatial (Guenther et al., 1993) and seasonal variability (Schade and Goldstein, 2003), so the $\beta$ values of $0.08^{\circ} \mathrm{C}^{-1}$ and $0.13^{\circ} \mathrm{C}^{-1}$ obtained by GCFID-REA and PTR-MS-EC, respectively, are within the expected range.

Fluxes from vegetation that store monoterpenes in resin ducts, like ponderosa pine, are typically modeled as solely temperature dependent. Monoterpenes emitted from broadleaved trees show a light dependence similar to that of isoprene. However, evidence for light and temperature dependence of emissions have also been reported for a few pine and spruce species, suggesting that monoterpene emissions may come from both stored pools and recently synthesized compounds (e.g. Kesselmeier and Staudt, 1999 and references therein; Rinne et al., 2002; Kuhn et al., 2002; Dindorf et al., 2005). The residuals from the best lognormal linear least squares fit between temperature and daytime (08:00-16:00 PST) total monoterpene flux measured by PTR-MS-EC showed a very slight, but statistically significant $(\mathrm{p}<0.01)$, positive relationship with photosynthetically active radiation (PAR). The residuals from the log-normal temperature fit to the sum of speciated monoterpene flux data measured by GC-FID-REA, however, showed no relationship with PAR, thus the very slight light dependence observed in the daytime total monoterpene flux may be a result of fragmentation of light dependent terpene emissions on the total monoterpene signal. However, without controlled measurements of emissions from ponderosa pine under varying temperature and light regimes, it is difficult to determine if the small positive correlation between the residuals and PAR is indeed real, and a result of interference from other terpene compounds. This potential interference from light dependent compounds is unrelated to the higher nighttime discrepancy between the total and sum of speciated mixing ratios because these compounds, if they are truly light dependent, would not be emitted at night.

\section{Conclusions}

The eight identified monoterpenes measured by GC-FID above the forest accounted for $\sim 70 \%$ of the total monoterpene mixing ratio and flux measured by PTR-MS. Six to ten additional peaks were resolved by the GC-FID; two of these peaks correlated with $\beta$-pinene and accounted for the daytime discrepancy between PTR-MS and GC-FID mixing ratios, and reduced the nighttime discrepancy to $20 \pm 2.9 \%$. Thus, despite the detection of eight identified and two unidentified potential monoterpenes, the PTR-MS still measured $\sim 20 \%$ more terpenes above the forest at night. The discrepancies between total and speciated flux measurements were not significantly different between day and night, likely because of the difficulties associated with nighttime flux measurements. The good agreement between PTR-MS and GC-FID mixing ratios during the day but not at night suggests that the additional compounds detected by PTR-MS were reactive enough to be oxidized before escaping the forest canopy, and undergo complete photochemical destruction before we can detect them during the day. This is consistent with the recent daytime observations of oxidation products in and above the forest canopy (Holzinger et al., 2005). Future work will focus on identifying the reactive terpenes emitted from ponderosa pine using the PTR-MS along with additional sampling and analytical techniques to improve measurements of higher molecular weight terpene compounds, like the sesquiterpenes. This current work shows that GCFID-REA measurements of speciated monoterpenes are in good agreement with simultaneous measurements of total monoterpenes by PTR-MS-EC, however, higher nighttime mixing ratios measured by PTR-MS suggest that additional very reactive terpene species are emitted from our field site and can be detected at night above the forest canopy by PTRMS.

Acknowledgements. This research was supported by the National Science Foundation Atmospheric Chemistry Program (award ATM-0119510), the California Air Resources Board (Contract 00-732), and the University of California Agricultural Experiment Station. A. Lee was supported by a Graduate Research Education Fellowship from DOE-GCEP. We thank B. Heald, D. Rambeau, $\mathrm{S}$. Rambeau, and the Blodgett Forest Crew for their invaluable support, D. Baldocchi, L. Misson, and D. Farmer for discussions on spectral analysis, and SPI for allowing us to conduct our research on their property.

Edited by: J. Kesselmeier

\section{References}

Andreae, M. O. and Crutzen, P. J.: Atmospheric aerosols: Biogeochemical sources and role in atmospheric chemistry, Science, 276 (5315), 1052-1058, 1997.

Bauer, M. R., Hultman, N. E., Panek, J. A., and Goldstein, A. H.: Ozone deposition to a ponderosa pine plantation in the Sierra Nevada mountains (CA): A comparison of two different climatic years, J. Geophys. Res.-A, 105 (D17), 22 123-22 136, 2000.

Bowling, D. R., Turnipseed, A. A., Delany, A. C., Baldocchi, D. D., Greenberg, J. P., and Monson, R. K.: The use of relaxed eddy accumulation to measure biosphere-atmosphere exchange of isoprene and of her biological trace gases, Oecol., 116 (3), 306-315, 1998. 
Dindorf, T., Kuhn, U., Ganzeveld, L., Schebeske, G., Ciccioli, P., Holzke, C., Köble, R., Seufert, G., and Kesselmeier, J.: Emission of monoterpenes from European beech (Fagus sylvatica L.) as a function of light and temperature, Biogeosci. Disc., 2, 137-182, 2005.

Fuentes, J. D., Lerdau, M., Atkinson, R., Baldocchi, D., Bottenheim, J. W., Ciccioli, P., Lamb, B., Geron, C., Gu, L., Guenther, A., Sharkey, T. D., and Stockwell, W.: Biogenic hydrocarbons in the atmospheric boundary layer: A review, Bull. Am. Met. Soc., 81 (7), 1537-1575, 2000.

Goldstein, A. H., Hultman, N. E., Fracheboud, J. M., Bauer, M. R., Panek, J. A., Xu, M., Qi, Y., Guenther, A. B., and Baugh, W.: Effects of climate variability on the carbon dioxide, water, and sensible heat fluxes above a ponderosa pine plantation in the Sierra Nevada (CA), Ag. For. Met., 101 (2-3), 113-129, 2000.

Greenberg, J. P., Guenther, A., Harley, P., Otter, L., Veenendaal, E. M., Hewitt, C. N., James, A. E., and Owen, S. M.: Eddy flux and leaf-level measurements of biogenic VOC emissions from mopane woodland of Botswana, J. Geophys. Res.-A., 108 (D13), 8466, doi:10.1029/2002JD002317, 2003.

Griffin, R. J., Cocker, D. R., Flagan, R. C., and Seinfeld, J. H.: Organic aerosol formation from the oxidation of biogenic hydrocarbons, J. Geophys. Res.-A., 104 (D3), 3555-3567, 1999.

Guenther, A. B., Zimmerman, P. R., Harley, P. C., Monson, R. K., and Fall, R.: Isoprene and monoterpene emission rate variability - model evaluations and sensitivity analyses, J. Geophys. Res.A., 98 (D7), 12 609-12 617, 1993.

Himejima, M., Hobson, K. R., Otsuka, T., Wood, D. L., and Kubo, I.: Antimicrobial terpenes from oleoresin of ponderosa pine tree Pinus ponderosa: A defense mechanism against microbial invasion, J. Chem. Ecol., 18 (10), 1809-1818, 1992.

Holzinger, R., Lee, A., Paw U, K. T., and Goldstein, A. H.: Observations of oxidation products above a forest imply biogenic emissions of very reactive compounds, Atmos. Chem. Phys., 5, $1-9,2005$,

\section{SRef-ID: 1680-7324/acp/2005-5-1.}

Karl, T., Potosnak, M., Guenther, A., Clark, D., Walker, J., Herrick, J. D., and Geron, C.: Exchange processes of volatile organic compounds above a tropical rain forest: Implications for modeling tropospheric chemistry above dense vegetation, J. Geophys. Res.-A., 109 (D18306), 1-19, 2004.

Kavouras, I. G., Mihalopoulos, N., and Stephanou, E. G.: Formation and gas/particle partitioning of monoterpenes photooxidation products over forests, Geophys. Res. Lett., 26 (1), 5558, 1999.

Kesselmeier, J. and Staudt, M.: Biogenic volatile organic compounds (VOC): An overview on emission, physiology, and ecology, J. Atmos. Chem., 33, 23-88, 1999.
Kuhn, U., Rottenberger, S., Biesenthal, T., Wolf, A., Schebeske, G., Ciccioli, P., Brancaleoni, E., Frattoni, M., Tavares, T. M., and Kesselmeier, J.: Isoprene and monoterpene emissions from Amazonian tree species during wet season: Direct and indirect investigations on controlling environmental functions, J. Geophys. Res.-A, 107 (D20), 8071, doi:10.1029/2001JD000978, 2002.

Lamanna, M. S. and Goldstein, A. H.: In situ measurements of C2-C-10 volatile organic compounds above a Sierra Nevada ponderosa pine plantation, J. Geophys. Res.-A., 104 (D17), 21247 $21262,1999$.

Lenschow, D. H. and Raupach, M. R.: The attenuation of fluctuations in scalar concentrations through sampling tubes, J. Geophys. Res.-A., 96 (D8), 15 259-15 268, 1991.

Lindinger, W., Hansel, A., and Jordan, A.: Proton-transfer-reaction mass spectrometry (PTR-MS): On-line monitoring of volatile organic compounds at pptv levels, Chem. Soc. Rev., 27 (5), 347 354, 1998

Makela, J. M., Aalto, P., Jokinen, V., Pohja, T., Nissinen, A., Palmroth, S., Markkanen, T., Seitsonen, K., Lihavainen, H., and Kulmala, M.: Observations of ultrafine aerosol particle formation and growth in boreal forest, Geophys. Res. Lett. 24 (10), 1219 1222, 1997.

Rinne, J., Hakola, H., Laurila, T., and Rannik, U.: Canopy scale monoterpene emissions of Pinus sylvestris dominated forests, Atmos. Environ., 34 (7), 1099-1107, 2000.

Rinne, H. J. I., Guenther, A. B., Greenberg, J. P., and Harley, P. C.: Isoprene and monoterpene fluxes measured above Amazonian rainforest and their dependence on light and temperature, Atmos. Environ., 36 (14), 2421-2426, 2002.

Schade, G. W. and Goldstein, A. H.: Fluxes of oxygenated volatile organic compounds from a ponderosa pine plantation, J. Geophys. Res.-A., 106 (D3), 3111-3123, 2001.

Schade, G. W. and Goldstein, A. H.: Increase of monoterpene emissions from a pine plantation as a result of mechanical disturbances, Geophys. Res. Lett., 30 (7), 1380, doi:10.1029/2002GL016138, 2003.

Schade, G. W., Goldstein, A. H., and Lamanna, M. S.: Are monoterpene emissions influenced by humidity?, Geophys. Res. Lett., 26 (14), 2187-2190, 1999.

Spirig, C., Neftel, A., Ammann, C., Dommen, J., Grabner, W., Thielmann, A., Schaub, A., Beauchamp, J., Wisthaler, A., and Hansel, A.: Flux measurements of biogenic VOCs during ECHO 2003, Atmos. Chem. Phys. Discuss., 4, 6603-6643, 2004, SRef-ID: 1680-7375/acpd/2004-4-6603.

Stull, R. B.: An introduction to boundary layer meteorology, Kluwer Academic Publishers, Boston, 1988.

Tani, A., Hayward, S., and Hewitt, C. N.: Measurement of monoterpenes and related compounds by proton transfer reaction-mass spectrometry (PTR-MS), Int. J. Mass Spec., 223 (1-3), 561-578, 2003. 